\title{
External Forces Impacting the Insurance Industry: Threats from Regulation
}

\author{
James J. Schiro \\ Zurich Financial Services, Mythenquai 2, CH-8022 Zurich, Switzerland. \\ E-mail: ceo@zurich.com
}

Regulatory interventions must be designed to meet economically sound goals. I argue that, although this may sound simple in theory, in practice it is not. Today's perpetually changing environment requires regulatory frameworks and processes to constantly adapt. At least for the insurance industry such regulatory responses - or a lack thereof when in fact they are needed - can be a serious source of risk. In this article, I highlight some of these threats that I believe to be of special importance. The process of designing new regulation is not always perfect. Too often regulators react to political pressure or regulation emerges through litigation and not in response to sound economic criteria. This can deeply impair contractual certainty and thereby entail far-reaching implications for the insurance industry. Another threat to insurance is that the design of regulatory frameworks increasingly fails to clearly distinguish insurance from banking and other financial services. This leads to the risk that the insurance industry will increasingly be forced to comply with regulation that is not optimally geared towards its business. Perhaps the most important threat though, is that regulation fails to recognize the integration of borderless markets. As markets continue to transcend borders, national regulation increasingly spills over from one local jurisdiction to another leading to the risk of conflicting regulations. Moreover, differing local regulations impair the realization of economies-of-scale and lead to excessive compliance costs. Local and regional regulatory solutions should be questioned and new approaches that span the supranational and global levels considered. Finally, I believe the only way to ensure that regulation will be flexible enough to keep up with the dynamics of insurance markets is for it to be principles-based as opposed to rules-based.

The Geneva Papers (2006) 31, 25-30. doi:10.1057/palgrave.gpp.2510064

Keywords: insurance; regulation; risk; principles-based regulation; market dynamics; globalization

\section{Introduction}

It is well-recognized that the insurance industry is fundamental to the welfare of our societies. Developed economies could not have emerged without risk sharing. Without insurance, society's capacity to mitigate risk would be limited and the protection of assets from catastrophic loss would be impaired. The industry's ability to innovate and to deliver insurance at competitive prices is crucial for all stakeholders.

Today's world presents serious challenges. Fundamental changes in natural, economic, social and political spheres, shifting stakeholder expectations and widereaching technological innovations lead to a perpetually changing and demanding risk environment. This calls for continuous adaptation from businesses around the globe. 
Since the nature of its business is risk mitigation, the insurance industry is particularly exposed and vulnerable to these external forces. Indeed, over the past 4 years, beginning with the terrorist attacks of September 11 and the near-meltdown of global equity markets, to the devastations caused by hurricanes in the U.S., the tsunami in Asia and flooding across Europe, the insurance industry has faced a series of challenges - challenges that are stark reminders that insurance is a highly volatile business. The insurance industry must deal pro-actively with all such external forces and continue to expand the frontiers of risk mitigation.

Yet it's not just businesses; regulatory frameworks and processes too must adapt. It is crucial that regulatory responses to the new challenges be well-designed and supportive of the economy. In fact, ill-designed regulatory responses, or the absence of any sound regulatory effort when in fact it is needed, present second-order risks in and of themselves. In this article, I will focus on these second-order risks arising from changes in regulatory environments. Whereas these do not appear as dramatic as other external forces do, they are nevertheless of utmost importance to the insurance industry.

Regulatory interventions must be designed to meet economically sound goals: they must correct for market failures, ensure systemic stability and protect the consumer. Regulation should complement markets by setting a framework within which efficient and sustainable markets can develop. Ultimately, the motivation of regulation must be to increase social welfare. This may sound simple in theory - however, in practice it is not. Designing optimal regulation poses serious challenges. To begin with, the process of designing new regulation must support the achievement of the ultimate goal of regulation. The costs and benefits of new regulation must be carefully weighed. A further practical problem is that the actual object of regulation is not always immediately obvious and regulation sometimes fails to recognize necessary differentiations. Regulation must be optimally geared towards the economic function that it aims to regulate. Furthermore, it must be consistent with the wider environment in which it regulates. This is especially important in the context of markets integrating into one global economy. Moreover, and related to the point above, regulation cannot be too stark. Just like business, in a world of constant change, regulation must adapt and respond to new challenges and, hence, it must be designed in a way that allows for sufficient flexibility. Regulation that is not optimally designed deters entrepreneurship and innovation and slows the rise of new wealth-creating business activities. It increases cost, induces misallocation of capital, fosters uncertainty, and leads to opportunity costs of diverted management time.

\section{Process of designing new regulation}

The first point I would like to make relates to the process by which new regulation is born. As already mentioned, the motivation for regulatory interventions must be to increase social welfare and the process of designing new regulation must support this goal. New regulation should not lead to specific interest groups being privileged on the back of others. Nor should it lead to a punishment of all for the wrong-doings of a few. 
Too often regulators react to political pressure and not in response to sound economic criteria. A corporate scandal shows up in the news, there is a public outcry, and regulators feel compelled to respond. For example, in the U.S., corporate scandals were quickly followed in 2002 by the introduction of Sarbanes-Oxley and the new listings rules of the New York Stock Exchange. Arguably, this is a classic example of regulation without concept of cost or benefit. Such ad hoc, damage-control methods of regulation are clearly not the way to design a regulatory structure that complements markets. How to reduce the risk of regulation that is purely reactive and made up on the spur of the moment is one of the bigger issues that must be confronted. Continuous evaluation with a full cost-benefit analysis is an important step toward "better regulation".

Recently, we have seen the emergence of regulation through litigation. Such regulation that is caused by an excessive tort system occurs with varying intensity across jurisdictions and is observable in many countries - but above all in the U.S. As it supplies products that have potential life spans of decades, the insurance industry depends on a degree of contractual certainty that regulation through litigation deeply impairs. Such litigation can be seen from the case of asbestos. Contractual uncertainty has far-reaching implications for the industry, undermining companies' relationships with customers and brokers, impairing established accounting practices, and stifling new product development. Inevitably, today's litigious culture has a profound impact on managing risk.

\section{The object of regulation: insurance vs. banking and other financial services}

With the rise of bancassurance, the line separating insurance from banking and other financial services has become blurred. The insurance industry has been increasingly stripped of its identity and is being perceived merely as a part of the financial services industry without many distinguishing features. The failure to clearly distinguish insurance from banking and other financial services has already influenced the design of regulatory frameworks. For example, by 2008, banks and insurers in Switzerland are set to come under the auspices of a single financial market supervisory body, FINMA - an arrangement that is already a reality in other markets such as the U.K., Germany, Austria, Japan, Canada and most Nordic countries. Clearly, there is a growing trend towards single financial market supervisory bodies. It is important to ensure that these bodies are equipped with strong insurance departments.

In terms of their specific regulatory needs, insurance and banking differ substantially. In particular, as compared to banking, primary insurance is, if at all, a much less important source of systemic risk. While a failure of the banking system, or an individual bank, spreads out over whole economies by endangering their payments systems, a failure of the insurance system and especially of a single insurance company is much less likely to generate a chain reaction. In addition, maturities of insurance contracts tend to be substantially longer than those of banking products. Liabilities from insurance contracts may extend over periods as long as $30-50$ years while the fixed terms of banking products such as loans rarely extend over periods exceeding 10 years. Hence - and this is a second critical difference 
compared with banking - insurance is far more exposed to contractual uncertainty than banking.

A failure to recognize the differences between insurance and banking leads to the risk that the insurance industry will increasingly be forced to comply with regulation that is not optimally geared towards its business, that is, insurance, not banking or other financial services.

\section{Coherency between regulation and the environment: the case of integrating markets}

Regulation must be consistent with the wider environment in which it regulates and, hence, regulatory frameworks and processes must adapt to changing environments just like business. Take globalization, for instance. As markets continue to transcend borders, national regulation increasingly spills over from one local jurisdiction to another - leading to the risk of conflicting regulations and regulatory arbitrage. Sarbanes-Oxley is a telling example. U.S. listing rules have consequences going far beyond the U.S. and provide a stark exemplification of the extraterritorial effects of U.S. regulation. To pre-empt such regulatory spillovers, it is imperative that the industry, legislators and supervisors follow market developments closely and cooperate where necessary to avoid conflicts of regulations. However, regulatory spillovers are not the only threat.

Perhaps even more important is the fact that the risks and opportunities arising from local regulatory responses to specific issues are often substantially different for the industry's international and global players than they are for its local players. While small, local players tend to favour local regulation that protects them from international competition, global players have an interest in regulatory responses that are consistent across a wide array of jurisdictions. For example, Zurich Financial Services operates in more than 50 retail markets and it has a strong interest that potential business synergies not be hampered by differing regulatory frameworks global operations only make sense if economies-of-scale indeed can be realized. Nor, of course, should the cost of compliance be unnecessarily high. In this perspective, the Optional Federal Charter in the U.S., the concept of convergence in the EU and the emergence of International Financial Reporting Standards (IFRS) are all steps in the right direction. Nevertheless, for regulation to keep up with market developments, there still remains a long way to go.

The following paragraph highlights some of the key practical issues faced by international insurance companies in the European Union, despite the EU's remarkable efforts to create regulation that supports an integrated market. In Europe alone, the industry operates in a market environment with more than 30 insurancerelated legislative, regulatory, and supervisory bodies. Evidently, and amplified by the inexistence of global government, on a global level the issues at hand are much more pronounced. Lifting regulation to higher levels is not a simple task.

Nevertheless, even in the EU, member states often fail to minimize add-ons to EU regulation ("gold plating"). Also, there are inconsistencies in the implementation of certain measures. For example, the Insurance Mediation Directive has been fully 
implemented in the U.K. and a few other member states only. The differences between the speed and level of implementation of EU legislation are considerable obstacles to cross-border trade and integration. The inability to write identical products in different member states leads to substantially more administrative work and costs as well as the need for different pricing mechanisms. The need for accounting and recordkeeping systems for each separate country also puts an additional burden on the financial and administrative functions of an insurance company. This problem is compounded by the variation in the rigor and robustness that national regulators apply to insurers and financial service regulation. For supervision to be efficient and effective, it must avoid duplication, and it must ensure that a firm is supervised according to the way in which it is managed. Many of the obstacles posed by the difference in national regulation could be overcome by the recognition of a lead regulator (i.e. the home regulator). The lead regulator approach is attractive because it removes duplication in supervision and it allows an international company to be regulated from the group level down. It is also flexible enough to allow for local regulators to play a part in supervision.

As a matter of principle, global goals should override local goals. While local and regional regulatory issues remain important, such regulatory solutions should be questioned and new approaches that span the supranational and global levels considered. This is especially important since many new risks stemming from developments such as climate change, nanotechnology or genetically modified organisms are global in scope. If, as seems likely, such global issues will not be sufficiently addressed by cooperation between governments, the insurance industry's ability to contribute to the welfare of society will be impaired.

\section{Regulation to match market dynamics}

From the above it has become clear that regulation must adapt to reflect the evolving demands from external forces. However, it is vital that such change comes at a moderate pace only. For example, in the EU, the number of new regulatory initiatives has increased over the past 5 years owing to the Financial Services Action Plan and dealing with many of its 42 measures has had a considerable impact on the insurance industry. Regulation must safeguard contractual certainty and grant businesses sufficient time to adapt to new regulation. In Europe, this has clearly been recognized by the Commission which has responded to the effort made by the industry in the Green Paper on Financial Services Policy (2005-2010). There will now be a focus on consolidation of existing legislation, rather than proposals for new initiatives.

All regulation faces a trade-off between the benefits arising from adapting to a changing environment and the costs emanating from the fast-paced introduction of new rules. Of course, this becomes more and more difficult the faster the environment changes. A possible way to manage this dilemma is through principles-based as opposed to rules-based regulation. It is, in my mind, the only way to ensure that regulation will be flexible enough to keep up with the dynamics of insurance markets. The reason is simple. To design rules for all possible contingencies would require a degree of prescience that is impossible to achieve in the real world. However, 
a principles-based approach will provide the flexibility to cope even with unanticipated situations. Of course, principles need to be accompanied by guidelines on acceptable standards of conduct, which may evolve over time. However, the attractiveness of a principles-based system is that it allows such evolution without the need for constant prescriptive legislation. A principles-based approach will also be equipped to cope with country-to-country differences and reduces the incentive for regulatory arbitrage. Dynamic markets need dynamic regulation to match.

\section{Summing up}

To sum up, the insurance industry must deal proactively with all external forces changes in natural, economic, social and political environments, shifting stakeholder expectations and wide-reaching technological innovations - so that it can continue to assume and expand its role in the economy. Regulation can make a major contribution towards meeting this goal, but it can also be an obstacle - hasty and ill-conceived regulatory responses to external forces represent second-order risks in and of themselves. Legislators and regulators must avoid ad hoc, damage-control regulation that is made up on the spur of the moment and both must be wary of the consequences of regulation through litigation. With respect to insurance, regulation must be specifically geared towards the business it regulates, that is, insurance, not banking or other financial services. Moreover, regulation must be reflective of globally integrating markets and the needs of global players, and regulators must keep alert to regulatory spillovers from one jurisdiction into others. Finally, to reflect the dynamics of markets, regulation should be principles-based as opposed to rules-based.

Ultimately, regulators and the industry share a common agenda to alleviate shortcomings of markets and to promote the efficiency of risk mitigation. Efforts to move towards more open and transparent consultation at all levels are crucial. It would behoove the leaders of our industry to promote dynamic regulation that responds to market forces, fosters innovation, and encourages self-regulation. We must take responsibility for freeing up competition by helping regulators help us.

\section{About the Author}

James J. Schiro (born 1946, U.S. Citizen) was appointed Chief Executive Officer of Zurich Financial Services (Zurich) in May 2002. Under his leadership, Zurich achieved a financial turnaround, pursuing a strategy of profitable growth based on a welldiversified portfolio of Life and General Insurance businesses. Previously James J. Schiro made a distinguished career at PricewaterhouseCoopers where from 1998 on he served as Chairman and Chief Executive Officer, leading it to be the largest global professional services firm. In addition to serving in the board of directors of PepsiCo and Royal Philips Electronics (as per October 1, 2005), James J. Schiro is active in a number of professional, international and civic organizations in Switzerland and the United States. He is a Certified Public Accountant and in 1995 he received an honorary doctorate of commercial sciences from St. John's University. 